\title{
Reconseptulaize Physical Activity Policy in Saudi Arabia Educational Curricula
}

\author{
Manal ObedAullah Alharbi \\ Prince Sattam Bin Abdulaziz University
}

\begin{abstract}
Author Note
Manal O. Alharbi is a Lecturer in the Early Childhood Education program at Prince Sattam Bin Abdulaziz University in Saudi Arabia. Manal Alharbi has worked as a kindergarten teacher in Saudi Arabia, and experienced training in American schools. Alharbi's research interests focus on early childhood policy, curriculum development, and play-based pedagogy. Alharbi is a strong advocate of play-based instruction which, in addition to supporting academic growth, remains holistic and most appropriate for young children's learning. Alharbi currently is perusing her doctorate in Early Childhood Education at the University of South Florida.

Contact: man.alharbi@psau.edu.sa
\end{abstract}

\begin{abstract}
This paper explains the current implementations of physical activity (PA) policies in Saudi Arabian schools beginning in early childhood and childcare settings. The paper explores the reasons for the new policy adopted by the Saudi Ministry of Education and the perspective of the Saudi society. Both the effectiveness of physical activity (PA) in preventing childhood obesity and its impact on children's health, development, and academic performance. An analysis of the recent steps taken by the Ministry of Education was conducted in this analysis paper. The Ministry of Education agreed on the change of the physical curriculum and the need to have a specific physical education/activity policy to accommodate every level of development, health, and the positive impact that children/students will have. The Saudi Ministry of Education shows promises in working toward the development. The Saudi society is also ready to change, and the Ministry of Education will continue to work to enhance the educational system as a part of the Saudi Vision 2030 initiative. The Ministry is still working on this approach and policy of physical education, and more research is needed in the area.
\end{abstract}

Keywords: physical education (PE), physical activity (PA), Saudi school, curriculum, policy, ministry of education.

DOI: $10.7176 / \mathrm{JEP} / 12-3-18$

Publication date: January $31^{\text {st }} 2021$

\section{Introduction}

Every country wants the best for its people and wants its people to give their best as well. Countries provide education, health insurance and services, support communities, jobs opportunities, and more to enable the people to give their best efforts. However, some countries lack some of these elements or have incomplete programs. This is normal, but it affects their people negatively in the long term.

Saudi Arabia provides many opportunities for its people. This developing country is moving quickly to make the Vision 2030 initiative a reality. The Saudi people are willing to change. They support and collaborate with their government in every step they take moving forward. As a member of the Saudi community who seeks this change with my government. As an early childhood educator, advocating for change in our educational policy by adding what we are missing in our curriculum and asking for development in our policies.

\section{RECRONCEPTULIZE PHYSICAL ACTIVITY POLICY IN THE SAUDI ARABIA EDUCATIONAL CURRICULA}

In 2012, as a previous kindergarten teacher in a small, humble private school, noticing that some children were physically healthy, but some were not. There was no specific time for physical activity. However, every morning with the children after circle time, doing some physical activity were effect to the psychological and physical health of the children. On the one hand, noticing that some children became happy and excited: their absences decreased, their attitudes changed, they were able to learn quickly, they became more confident, and their focus became stronger. On the other hand, some children were overweight and did not exercise effectively like their peers. They breathed rapidly and quickly became tired. Because of this incident, deciding to advocate against childhood obesity in an educational way by asking to provide a curriculum in "Physical Activity and Education" in the Saudi school system beginning in the early childhood setting is my taken step. Additionally, advocating for preparing qualified teachers for every level of development. Howells, Wellard, and Woolf-May (2018) said that the school setting is considered a golden key in promoting physical activity (PA). However, there is an absence of knowledge regarding a particular physical activity levels that the teachers could apply to their students (Howells et al., 2018). 
The lack of physical education (PE) in Saudi Arabian schools has had a negative impact on our people; men, women, young, and adult. Some adults in Saudi Arabia do not like to exercise, and they suffer from obesity because they did not exercise when they were younger. This spotlights the importance of PE in our schools for building a healthy generation starting at the pre-school level. According to Duffey, Slining, and Neelon (2014) "Child care facilities' policies can importantly impact health behaviors of toddlers and preschoolers."

Obese and overweight students face academic difficulties, low self-esteem, social-emotional problems, bullying, and health problems. According to the World Health Organization (2018), in 2016, indicated that around 41 million children of age 5-years were obese or overweight.

Enhancing and enriching PE is an issue not only in Saudi schools, but also in schools in countries worldwide, such as the United States of America, Canada, the United Kingdom, China, Africa, and the Middle East. The percentages of obese children increase every year, making it a world health problem. Many studies suggested that most children become obese or overweight when they begin elementary school. Starting PE in the early childhood setting can mitigate this. Besides spending their days playing and learning, it is essential that pre-school students spend 60 minutes exercising: moving, dancing, and doing physical activities every day. "PE lessons have been seen as the most suitable vehicle to encourage healthy and physical active lifestyles" (Howells et. al., 2018).

The Ministry of Education has decided to include PE curriculum in all Saudi schools at all levels. This might not be something new to all Saudi students. However, it is new for more than 5 million students. Schools in Saudi Arabia are divided into three categories: international, private, and public. International schools provide PE to their students as well as some of the private schools. However, public schools do not provide PE in girls' schools, and in some boy's schools PE is provided ineffectively. More than half of all Saudis are educated in our free public schools, so without providing effective PE, the problem of obesity will not be eliminated. What is most needed is the teaching and offering of a major in PE/PA at our Saudi universities. In this way, we can train educators in PE and specialists at every level of development, from infancy to adolescence, with an emphasis on children 0-8 years old.

The educational environment and early child care have become essential targets in preventing childhood obesity. Kain, Leyton, Soto-Sanchez, \& Concha (2018) emphasized that "Within school time, the physical education lesson (PE) has been identified as the most important segment to intervene, as it is the only curricular subject to provide physical activity (PA) to all the children." Increasing children's fine motor skill proficiency is essential to increasing physical activity in their school day (Kain et al., 2018).

Gender differences in PE performance are clearly demonstrated in that girls do not participate as much as boys. Kain et al. (2018) provided an example showing the differences in PE participation rates between boys and girls in some countries. For instance, in Brazil, $44.1 \%$ of boys and $21 \%$ of girls participated in PE classes; $42 \%$ of boys and $27 \%$ of girls participated in PE classes in Hong Kong (Kain et al., 2018).

According to Aljaaly (2017), 71\% of Saudi children and adolescents do not meet the necessary minimum requirements for physical activity. Girls are less involved in physical activities, exercises, and sports than boys (Aljaaly, 2017).

Physical activity can be easily added in early childhood settings. Duffey et al. (2014) indicated that early childhood educators and child care workers can provide opportunities throughout the day for infants, toddlers, and preschoolers to be physically active. Establishing indoor and outdoor environments with playground equipment and enough space for each child would positively benefit children's physical play (Duffey et al., 2014).

Changing, adding, enhancing, and enriching PE curriculum in all Saudi schools will eliminate the negative effects on students' health, development, academic performance, and social lives. The Ministry of Education has taken some important steps to start working toward the goal of enhancing and applying PE equally in all Saudi schools. Additionally, the Saudi community is willing to change and ready to participate in this essential curriculum.

The Saudi Ministry of Education has taken important steps in developing the PA/PE curriculum and applying it in all schools, including early childhood settings. Some of their steps are as follows:

* Setting up gyms in schools

* Providing qualified physical education female competencies

* Recreate the PA approach

* Establishment of a supervisory committee to implement the program, headed by the undersecretary of the Ministry of Education for Girls, Dr. Haya Alawad

* Establishment of the program guidelines by the committee, including objectives and performance indicators

* Preparation of a phased implementation plan

* Working with universities to prepare specialists to contribute to the implementation of the program and coordinate with authorities to complete the requirements

* Follow-up implementation in the educational field

* Providing the committee chair, Dr. Haya Alawad, the ability to use what means she sees 
fit to complete the program implementation

* Working to provide technical and human capabilities

* Calculation of the costs of rehabilitating gyms in schools

* Calculating the costs of establishing and equipping new gyms

All these steps are essential for the implementation of the PE curriculum. However, these steps will take a long time to complete. To make the long way short, the Ministry of Education created another solution to allow schools to start PE earlier while working on the previous steps. These early solutions are as follows:

* Providing a one-year diploma course to prepare educators to teach PE

* Contracting with private companies in the field of sports development and rehabilitation to cooperate with the Ministry of Education and Saudi universities

* Hosting monthly workshops for early childhood teachers on effective PE instruction for children

In the past, physical activities were not allowed in girls' public schools (Aljaaly, 2017). In addition, Aljaaly (2017) said that a physical education curriculum was not considered in Saudi classes because of beliefs and social norms. Saudi girls used to - and still do - commute to school every day as a way to exercise and move (Aljaaly, 2017). Despite the absence of PE at some girl's schools, some health fitness centers were designed for girls and women to exercise after the school day (Aljaaly, 2017).

Many centers now are designed especially for families to engage in physical activity with their children. Outdoor activities are developed by the government to encourage families to engage with their children and exercise. These activities and facilities include swimming pools, football playgrounds, neighborhood playgrounds, neighborhood walkways, gymnastics classes, karate classes, city-rental bicycles, and more free and low-cost activities that every child and family can do.

The steps that the Ministry of Education has taken toward its goals have varying levels of effectiveness. Effective steps included:

* Collaborate with the universities to train current teachers.

* Enhance the school environment.

* Make a development plan.

* Make workshops for teachers.

* The Saudi community welcomed the new change

* Students/children were happy and excited to exercise with their peers

* Both educational institutions and families are aware of the positive impact on our children from this new curriculum

Ineffective steps were:

* Discuss the topic generally, without specifying different levels.

* Rebuild or expand some schools.

* Create a general PE curriculum that does not meet different developmental needs.

* Require physically unqualified teachers to do PA with children.

* Some teachers do not apply PA with children as it should be.

* Restrict the input of schools on the curriculum unless they have the permission of the Ministry of Education.

\section{ANALYZING THE IMPLEMENTATIONS OF THE CURRENT POLICY CONTEXT TAKEN BY THE SAUDI MISTRY OF EDUCATION}

The Saudi Ministry of Education realized the importance of PE/PA at all educational levels and specially in the childhood field $(0-8)$ years-old. It is clear that the Ministry of Education is trying to benefit from its past experiences in PE. However, they should keep an eye on the differences between each level of development. Every level requires a different approach. Specialists in PE/PA can help establish the right curriculum and policy for each educational level, taking into consideration the differences in capabilities and physical and mental health. Building relationships and collaborating with partners from outside the Ministry both locally and internationally would help with this transformation and with creating strong policies.

\section{RECOMMENDATIONS}

Duffey et al. (2014) indicated that every child care and educational setting should provide children the opportunity to be physically active. The environment of the community must also promote children's physical activity, educators should allow children to move freely, and training should be provided to decrease children's inactivity and increase children's physical movement (Duffey et al., 2014).

To promote best practices in physical activity; it is important to anchor or fix the outdoor play equipment, provide wheeled toys, and provide opportunities for indoor play that promote gross motor movement (McWilliams, Ball, Benjamin, Hales, Vaughn, \& Ward, 2009).

From knowledge, readings, and experiences in the field of education especially in the early childhood setting, 
in general and higher education, a summary of some recommendations that can facilitate implementing effective PA in Saudi schools:

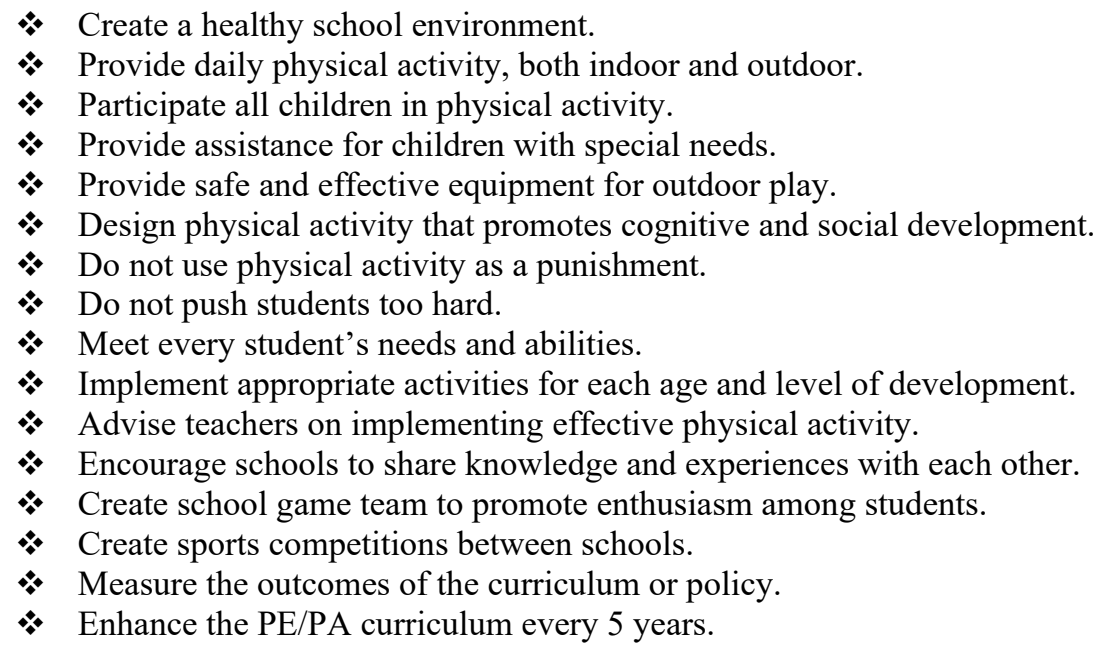

\section{DISCUSSION \& CONCLUSION}

This paper summarizes the changes that the Saudi Ministry of Education is making to promote the educational development of the country and the Saudi Vision 2030 initiative. In addition, the positive perspective of the Saudi community "Leaders, educators, and families" promote enormous changes in the country.

Through an official PE/PA policy, the effectiveness of the implementation of PA would be notable and measurable. Also, considering differences in; age differences, gender, abilities, and the needs of special needs children would maintain the success of this approach. Applying successes from past experiences would help in this stage. Everyone has agreed on the positive effect of the physical activities in our future generation health, development, academic performance, and personality, as well as having a policy or a curriculum in PA starting from an early age.

As part of the Saudi Vision 2030, generalizing the PE curriculum in the Saudi school at all levels of education is a new and courageous step taken by the Ministry of Education. Creating a policy in this context is also new and essential step. As the Ministry is still working on this approach and policy, more research is needed on the implementation of the policy for each educational level.

\section{ACKNOWLEDGMENT}

In appreciation of the blessings that I have, I would like first to thank GOD then my family for their great support. Also, great appreciation goes to my country Saudi Arabia, representing by Prince Sattam Bin Abdulaziz University and Saudi Arabia Cultural Mission in the United States for funding my scholarship.

\section{REFERENCES}

Aljaaly, E. A. (2017). Physical Activities of Young Girls in Jeddah, Saudi Arabia. Arab Journal of Nutrition and Exercise (AJNE), 1(3), 122. doi:10.18502/ajne.v1i3.1229

Duffey, K. J., Slining, M. M., \& Neelon, S. E. (2014). States Lack Physical Activity Policies in Child Care That Are Consistent with National Recommendations. Childhood Obesity,10(6),491-500. doi:10.1089/chi.2014.0096

Howells, K., Wellard, I., \& Woolf-May, K. (2018). Young children's physical activity levels in primary (elementary) schools: What impact does physical education lessons have for young children? Early Child Development and Care, 1-12. doi:10.1080/03004430.2018.1490899

Kain, J., Leyton, B., Soto-Sánchez, J., \& Concha, F. (2018). In preschool children, physical activity during school time can significantly increase by intensifying locomotor activities during physical education classes. BMC Research Notes, 11(1). doi:10.1186/s13104-018-3536-x

Mcwilliams, C., Ball, S. C., Benjamin, S. E., Hales, D., Vaughn, A., \& Ward, D. S. (2009). Best-Practice Guidelines for Physical Activity at Child Care. Pediatrics, 124(6), 1650-1659. doi:10.1542/peds.2009-0952

Ministry of Education. (n.d.). المملكة العربية السعودية $\quad$ Retrieved from https://www.moe.gov.sa/ar/news/Pages/edu- sport.aspx

Obesity and overweight. (n.d.). Retrieved from http://www.who.int/news-room/fact-sheets/detail/obesity-andoverweight 